\title{
A CONSTRUÇÃO SOCIAL DE GÊNERO PARA CRIANÇAS ATRAVÉS DO YOUTUBE
}

SOCIAL GENDER BUILDING FOR CHILDREN THROUGH YOUTUBE

\section{Maria Clara Monteiro ${ }^{1}$}

RECEBIDO EM: 05/02/2020 | ACEITO EM: 01/03/2020

DOI: $10.5902 / 2317175842394$

\section{RESUMO}

O consumo de vídeos do YouTube vem se popularizando com as crianças, que desde cedo podem ter acesso à Internet através de smartphones, tablets, smart $T V s$ e computadores. Assim, os conteúdos publicados e compartilhados se tornam parte do repertório midiático consumido pelas crianças, o que também inclui formas de aprendizagem sobre a sociedade, como comportamentos e marcadores de gênero. Este artigo propõe analisar qualitativamente como meninos e meninas entre nove e 11 anos constroem seus marcadores de gênero com base no consumo midiático do YouTube. Percebemos que elas consomem conteúdos de acordo com suas noções de feminino e masculino e o YouTube é uma representação social das normatizações impostas por essa dicotomia de dois tipos de gênero.

Palavras-chave: Infância; YouTube; Gênero; Nativos digitais. 
A CONSTRUÇÃO SOCIAL DE GÊNERO PARA CRIANÇAS ATRAVÉS DO YOUTUBE

\section{ABSTRACT}

Consuming YouTube videos has become popular with children, who can access the Internet through smartphones, tablets, smart TVs, and computers from an early age. Thus, published and shared content becomes part of the media repertoire consumed by children, which also includes forms of learning about society, such as behaviors and gender markers. This article proposes to analyze qualitatively how boys and girls between 9 and 11 years old build their gender markers based on YouTube media consumption. We realized that they consume content according to their notions of feminine and masculine and YouTube is a social representation of the norms imposed by this dichotomy of two types of gender.

Keywords: Childhood; YouTube; Genre; Digital Natives.

\section{Introdução}

As práticas socioculturais são afetadas cada vez mais pelos usos de dispositivos como smartphones, tablets e notebooks conectados à Internet para a comunicação e o consumo de conteúdo. Com as crianças não seria diferente. Elas estão inseridas nessa lógica tecnológica da conectividade e o consumo de conteúdos através desses dispositivos pode afetar seus aprendizados, a socialização e as construções de seus papéis sociais.

Dentro deste contexto, as crianças nascem numa época em que a Internet e as tecnologias digitais estão presentes constantemente no cotidiano e supostamente elas já saberiam se conectar à Web, assistir a vídeos, jogar on-line, baixar aplicativos nos seus celulares etc. Porém, esse conceito, apesar de amplamente usado, não significa que as crianças tenham a visão crítica dos conteúdos que consomem, e isso inclui também as representações sociais apreendidas nas produções disponíveis no ambiente on-line.

Nesse cenário, temos o site de rede social de compartilhamento de vídeos, o YouTube. O Brasil é o segundo maior consumidor de vídeos no YouTube, sendo o dispositivo móvel (smartphone) mais utilizado para o acesso. Segundo os dados do YouTube, o brasileiro assiste uma média de mais de $15 \mathrm{~h}$ de vídeos por semana. A pesquisa "Video Viewers" informou que a plataforma é o principal local de consumo de vídeos on-line, perdendo somente para o player da TV Globo, no Brasil, sendo a principal motivação para a procura de conteúdos, o entretenimento (MARINHO, 2018).

Um dos motivos do sucesso do YouTube é o fato dele representar o ápice da cultura participativa (JENKINS, 2009), ou seja, todos nós somos consumidores e produtores de conteúdos na Internet. Com isso, surge a figura dos YouTubers, produtores de conteúdo profissionais para o YouTube. Seus canais atingem popularidade com milhões de inscritos e falam diariamente, através de seus vídeos, assuntos escolhidos pelos YouTubers, muitas vezes mais focados nos números de visualizações do que na qualidade do conteúdo em si. 
Assim, o YouTube, como parte do cotidiano das crianças, se torna uma fonte de conhecimento para elas, inclusive em relação aos marcadores de gênero (SWAN, 1992; SOUZA, 2006), isto é, a plataforma provê conteúdos midiáticos que ajudam a formar suas representações sobre o que deve ser consumido por meninas e meninos, determinando seus gostos e comportamentos sociais.

Logo, considerando a importância de estudar a infância no âmbito comunicacional, este projeto pretende avançar nas questões relacionadas ao gênero permeadas pelo consumo cultural do YouTube. Por isso, o presente artigo visa problematizar como meninos e meninas entre nove e 11 anos constroem seus marcadores de gênero com base no consumo midiático do YouTube.

\section{Referencial teórico}

\subsection{Crianças como nativas digitais: o consumo tecnológico da Internet}

As crianças são consideradas "nativos digitais" (PRENSKY, 2001; PALFREY; GASSER, 2008) por nascerem na sociedade contemporânea marcada pelo intenso uso das tecnologias digitais. Assim, é atrelada à infância contemporânea essa suposta familiaridade com esses dispositivos e o ambiente on-line. Importante salientar que o termo "infância" no singular se refere à categoria social (QVORTRUP, 2010), historicamente criada para valorizar as especificidades das crianças e como forma de garantir direitos sociais para elas. Por isso, a infância está em constante mudança de acordo com a sociedade e a cultura. Não é uma categoria fechada, mas sim fluida, uma invenção histórica (SOUZA, 2009), tentando abarcar as diferenças sociais.

Assim, Qvortrup (2010) acredita que a infância está sob a influência de fatores socioculturais, tecnológicos, ideológicos e históricos. A categoria existe como identidade da criança e como período de desenvolvimento/crescimento. Por isso, afirmamos que infância se trata, na verdade, de um processo social complexo que vai além da criança, englobando os fatores citados e também representações infantis e midiáticas.

Por ser essa categoria social, a infância pode ser vista de diferentes ângulos desde as imagens midiáticas até o ambiente escolar em diversas realidades culturais. Isso implica perceber no discurso da criança como a família, os pares, os outros adultos e as instituições sociais determinam suas práticas (ALCÂNTARA, 2017). Também entram como aspectos compositores desta categoria as tecnologias comunicacionais e midiáticas (FELIPE; GUIZZO; BECK, 2013) como a televisão e a Internet, que permite o compartilhamento de informações entre as crianças e diferentes aprendizados sobre o mundo, além de proporcionar vínculos sociais e afetivos através da comunicação on-line nas redes sociais digitais. "As representações que a criança vai construindo acerca da internet em suas vivências são partilhadas entre seus pares, fazendo parte da cultura lúdica de todo um grupo de crianças que participam daquele contexto" (ALCÂNTARA, 2017, p. 162). 
A CONSTRUÇÃO SOCIAL DE GÊNERO PARA CRIANÇAS ATRAVÉS DO YOUTUBE

Logo, esse entrecruzamento entre tecnologias e nativos digitais se configura à ideia de que elas têm competências, no sentido de conhecimentos e habilidades para produzirem e consumirem conteúdos on-line. Isso é tomado como uma familiaridade consequente da alta conectividade à Internet pelos aparelhos como smartphones, tablets, smartTV, computadores e videogames.

Nativos digitais vivem muito de suas vidas on-line sem distinguir entre on-line e o offline. Ao invés de pensarem na identidade digital e na sua identidade real-espacial como coisas separadas, eles pensam somente em uma identidade (com representações nos dois, ou três, ou mais diferentes espaços). Eles estão reunidos por um conjunto de práticas em comum, incluindo a quantidade de tempo que gastam utilizando tecnologias digitais, a sua tendência a multitarefas, a sua tendência de se expressarem e relacionarem uns com os outros de maneira mediada pelas tecnologias digitais, e seu padrão de uso das tecnologias para ter acesso, usar as informações e criar novo conhecimento e novas formas de arte (PALFREY; GASSER, 2008, p.4, tradução nossa).

Porém, as crianças sabiam manusear os aparelhos, smartphone e computadores, no nível mais básico, ou seja, tinham conhecimentos sobre botões, formas de pesquisar no YouTube e pular os comerciais antes dos vídeos. Elas não apresentaram senso crítico em relação aos conteúdos visualizados. Desta forma, mesmo que as crianças sejam consideradas "nativas digitais", isso não quer dizer que elas reflitam sobre os usos e as apropriações que fazem dos conteúdos on-line (FANTIN, 2016). Além disso, não podemos esquecer que as mídias e seus conteúdos contribuem na difusão de valores culturais e comportamentos aceitos pela sociedade.

Assim, não é possível afirmar que todas as crianças são nativas digitais com plena familiaridade com a Internet e dispositivos tecnológicos. Pompeu (2014, p. 252) corrobora este raciocínio ao afirmar que "as novas tecnologias, plasmadas nas redes sociais da Internet, estão inaugurando uma nova forma de manuseio da linguagem - e, portanto, do pensamento - que requerem estudos aprofundados e cuidadosos" e por isso, buscamos entender como meninos e meninas interpretam seus papéis sociais mediados pelos conteúdos midiáticos digitais do YouTube.

\subsection{YouTube: da cultura participativa ao consumo cultural}

A plataforma digital do YouTube, inaugurada em 2005 e atualmente pertencente à empresa Google, é uma das mais populares de streaming de vídeos. "Milhões de usuários em todo o mundo incorporaram o YouTube e o compartilhamento de vídeos em seus hábitos e rotinas cotidianas" (DIJCK, 2013, p. 129, tradução nossa). Para Snickars e Vonderau (2009), a popularização do YouTube se deve pela potencialidade para os formatos de vídeos 
digitais, de compartilhamentos, de comentários, de publicidade e pela abertura para que qualquer pessoa faça suas produções e as publique. Assim, a plataforma se caracteriza como um acervo imagético jamais visto em outras mídias. O YouTube apresenta a capacidade de alcance de diferentes públicos, de adultos a crianças.

A plataforma se caracteriza como rede social digital por permitir um espaço conversacional com comentários e compartilhamentos (BOYD; ELISSON, 2007). É um lugar de exploração de novos conteúdos nos âmbitos da produção, do consumo de vídeos e da conversação entre sujeitos. O incentivo à produção de materiais pelos sujeitos faz parte da lógica do YouTube, o "broadcast yourself", que dialoga com o conceito de prosumers (TOFFLER, 1980) e da cultura participativa (JENKINS, 2009). Toffler acreditava que os consumidores virariam produtores de conteúdo, o que é implementado com as redes sociais digitais. Portanto, qualquer sujeito é potencialmente produtor de informação e não somente consumidor dela (OROZCO GOMEZ, 2014). O YouTube segue esse princípio, elegendo "sistema interno de celebridades" composto pelos YouTubers (BURGESS; GREEN, 2009), isto é, produtores de conteúdo para a plataforma. Isso tudo faz parte do que Jenkins chamou de cultura participativa.

A expressão cultura participativa contrasta com noções mais antigas sobre a passividade dos espectadores dos meios de comunicação. Em vez de falar sobre produtores e consumidores de mídia como ocupantes de papéis separados, podemos agora considerá-los como participantes interagindo de acordo com um novo conjunto de regras, que nenhum de nós entende por completo (JENKINS, 2009, p. 30).

Por ser um processo sociocultural e tecnológico (JENKINS; ITO; BOYD, 2016), existem diferentes visões sobre a participação dos sujeitos nas mídias. Palfrey e Gasser (2008, p. 125) apresentam uma opinião otimista em relação à cultura da participação, pois acreditam que "a tecnologia digital dá a todos os meios para se expressar, e capacita-os a falar - e a serem ouvidos por outros, incluindo aqueles que estão no poder - de maneiras que gerações anteriores poderiam ter imaginado". Eles acreditam que a possibilidade de mais sujeitos produzindo conteúdo gera mais diversidade cultural no ambiente on-line. Já Jenkins, Ito e Boyd (2016) criticam essa exaltação da tecnologia como proporcionadora de participação democrática para todos os sujeitos. Por mais que existam novos dispositivos e empresas tecnológicas, ainda estamos numa lógica capitalista que não provê acesso para todos e nem educação para análise crítica dos conteúdos midiáticos.

A promoção da cultura participativa no YouTube é uma estratégia de divulgação e de estímulo à produção de conteúdo de acordo com os interesses empresariais, o que significa que os vídeos são fontes de comunicação e de monetização para a plataforma através dos anunciantes. Isso ocorre pelo 
A CONSTRUÇÃO SOCIAL DE GÊNERO PARA CRIANÇAS ATRAVÉS DO YOUTUBE

controle exercido pelos algoritmos, que determinam os conteúdos a serem assistidos para cada usuário (DIJCK, 2013). A plataforma consegue assim coletar dados e sugerir mais vídeos, criando perfis de cada um dos sujeitos. Um exemplo empírico disso é o fato que as crianças, ao mostrarem determinado vídeo, apontavam para os relacionados, dizendo o que já haviam assistido. Os algoritmos entendem que, ao verem uma quantidade $X$ de vídeos de dança, como os dos canais Cia. Daniel Saboya, ou de gameplay de GTA, estes são assuntos que as interessam e sugere mais opções de vídeos dos mesmos canais ou semelhantes. Logo, quanto mais a criança assistir a determinado conteúdo, mais ela vai ter material para construir representações sociais, se apropriando das imagens e das linguagens vistas nos vídeos. Importante salientar que o termo "apropriação" está relacionado ao processo do consumo (CANCLINI, 1999a), abrangendo a produção de sentido do sujeito. Ou seja, a partir do consumo de um produto cultural (CANCLINI, 1999b), como os vídeos no YouTube, as crianças criam seus próprios significados sobre o mundo, inclusive sobre os marcadores de gênero.

"Os produtos denominados culturais têm valores de uso e de troca, contribuem para a reprodução da sociedade e às vezes para a expansão do capital, mas neles os valores simbólicos prevalecem sobre os utilitários e os mercantilizáveis" (CANCLINI, 1999B, p. 42, tradução nossa). Desta forma, pensar no consumo cultural significa compreender os valores simbólicos, e no caso das mídias os produtos como os vídeos do YouTube são provocadores de diferentes sentidos apropriados pelos sujeitos. França $(2012$, p. 12) vai além ao afirmar que

a mídia constitui talvez a instituição que melhor caracteriza o cenário contemporâneo; a face da nossa sociedade, nosso comportamento, nossas ações são hoje o que são porque dispomos de tais meios, espaços, instrumentos para nos informarmos, nos exprimirmos, formatarmos nossas ações e nosso cotidiano.

Assim, desde a infância, os sujeitos consomem culturalmente os conteúdos midiáticos. Por isso, as mídias possuem impacto sociocultural na produção de sentidos sobre a sociedade. Isso fez as autoras Toaldo e Jacks (2013) proporem o consumo midiático como uma especificidade do consumo cultural de Canclini (1999b). Para as autoras, ele seria o consumo oferecido pelas mídias, englobando processos de apropriação e de ressignificação dos produtos midiáticos pelos sujeitos.

No cenário de convergência midiática e digital (JENKINS, 2009), é difícil pensar que estes dois tipos de consumo possam ser identificados separadamente. Ambos estão imbricados na complexidade da apropriação dos conteúdos. Estes tipos de consumos estão presentes nos cotidianos das crianças através do YouTube e seus conteúdos. Eles fazem parte do que Corsaro (2011) chama de "cultura simbólica", ou seja, conteúdos midiáticos, literatura e mitos e lendas, apropriados pelas crianças de diferentes formas através da reprodução interpretativa: 
O termo interpretativo abrange os aspectos inovadores e criativos da participação infantil na sociedade. [...] as crianças criam e participam de suas próprias e exclusivas culturas de pares quando selecionam ou se apropriam criativamente de informações do mundo adulto para lidar com suas próprias e exclusivas preocupações. O termo reprodução inclui a ideia de que as crianças não se limitam de internalizar a sociedade e a cultura, mas contribuem ativamente para a produção e mudanças culturais (CORSARO, 2011, p. 31-32).

Desta forma, as crianças elaboram suas próprias práticas de acordo com as informações do mundo aprendidas. A brincadeira é uma forma das crianças praticarem a reprodução interpretativa, pois ela mescla fantasia com realidade, permitindo que ela vivencie, produza significados, aprenda sobre sua cultura (ALCÂNTARA, 2017). Outra forma é incentivar a criança, através da conversa, a demonstrar suas opiniões sobre determinados assuntos, como os vídeos de jogos ou de maquiagem. A construção do papel social da criança é feita a partir dessa mescla de interações tanto com os pares, com os adultos e com as mídias através da reprodução interpretativa.

Deste modo, foi possível refletir sobre o entrelaçamento das práticas culturais com as escolhas dos vídeos do YouTube. Logo, podemos elencar características da plataforma que facilitaram o consumo cultural e midiático dos conteúdos pelas crianças.

A primeira é que os YouTubers falavam diretamente para a câmera e interagiam com o público pelos pedidos de comentários, inscrições e likes, dando a ilusão de proximidade com a criança através da tela (LANGE, 2009; OROZCO GOMEZ, 2014). As participantes acreditavam no que os YouTubers mostravam e afirmavam, sendo estes vistos como "amigos" e formadores de opinião. Aliado a isso está o fato das crianças assistirem aos vídeos sozinhas, principalmente em smartphones e quase diariamente.

Outro atrativo do YouTube é a possibilidade de encontrar diferentes tipos de informação, verídicas ou equivocadas, voltadas para todos os públicos, dada a infinidade de assuntos publicados nos vídeos. Assim, o YouTube favorece a "aprendizagem informal" (FANTIN, 2018), isto é, os sujeitos podem aprender a qualquer momento, sobre qualquer coisa graças aos vídeos. As crianças relataram terem aprendido a dançar, a jogar GTA, futebol e a se maquiar. Porém, elas não apresentaram uma análise crítica desses conteúdos e sim um interesse em reproduzi-los e dividir esses conhecimentos com outras crianças.

Por último, o YouTube é umas das principais fontes de entretenimento para a criança. Ao sugerir vídeos com assuntos interligados, ele facilita a permanência dos sujeitos por mais tempo visualizando conteúdos e, consequentemente, coletando mais de seus dados. Logo, o entretenimento em diferentes tipos de vídeos é oferecido às crianças e aos adultos em troca de suas informações.

3 Em contraposição, a aprendizagem formal, proporcionada pela escola e desenvolvida na sala de aula com a figura do professor. 
Esses elementos da plataforma são importantes para a compreensão de como o YouTube influencia o consumo de vídeos pelas crianças e, por conseguinte, a apropriação dos conteúdos que envolvem diferentes aspectos sociais como comportamentos e normas dentro das construções de gênero.

\section{Método de pesquisa}

A metodologia escolhida foi qualitativa, ou seja, não pretendíamos quantificar, mas sim entender os significados das respostas (ROSA; ARNOLDI, 2008) para buscar analisar subjetivamente as respostas das crianças sobre $O$ consumo do YouTube.

O campo empírico envolveu entrevistas semiestruturadas com 15 crianças (sete meninas e oito meninos) de duas escolas públicas de Porto Alegre com idade entre dez e 11 anos, faixa etária limiar da pré-adolescência. Além disso, elas são ávidas consumidoras do YouTube, segundo a pesquisa TIC Kids Online Brasil 2018 (NIC.br, 2019). Escolhemos fazer a pesquisa no ambiente escolar por ser um ambiente que as crianças já estavam familiarizadas e não teria a interferência dos pais nas respostas delas.

De acordo com Flick (2009), a entrevista semiestruturada se caracteriza pelo pesquisador decidir a ordem das perguntas que podem ser abertas e pré-determinadas em formato de roteiro. Rosa e Arnoldi (2008, p. 31) apontam que este último permite que se "discorra e verbalize seus pensamentos, tendências e reflexões sobre os temas apresentados". Assim, a entrevista semiestruturada apresenta flexibilidade para seguir com o fluxo das respostas dos participantes, é a mais interessante para trabalharmos com as crianças, permitindo mudanças e aprofundamentos quando necessários.

Para fins de análise, o roteiro de perguntas foi estruturado para, em um primeiro momento, as crianças apresentarem informações sobre com quem moram, acesso à Internet, aparelhos utilizados para assistir aos vídeos, canais do YouTube, frequência e quais vídeos assistidos. Como procedimento para entrevista, pedíamos para elas sentarem na frente do computador ou utilizarem o smartphone da pesquisadora para escolherem seus vídeos favoritos enquanto respondiam às perguntas.

\section{Apresentação e discussão dos resultados}

\subsection{Gênero e consumo no YouTube: divisões entre meninos e meninas}

Com base nessas características do YouTube, precisamos então analisar como as questões de gênero aparecem nas falas das crianças entrevistadas através do consumo que elas fazem dos vídeos. Por isso, é importante desenvolvermos neste tópico o conceito de gênero. Concordamos com Scott (1995, p. 75) que pensar em gênero envolve compreender "construções culturais" sobre os papéis sociais divididos entre homens e mulheres. 
Sayão desenvolve essa ideia ao afirmar que "o gênero inclui o sexo biológico a partir dos valores e atributos que determinada cultura the confere e analisa as construções sociais sobre o masculino e o feminino que são produzidas nas diferentes sociedades" (SAYÃO, 2003, p. 71). Em outras palavras, discutir sobre gênero significa investigar como são ensinadas, desde a infância, práticas, normas sociais e comportamentos para moldar os sujeitos dentro do espectro de representações de feminino e de masculino, buscando problematizar juntamente com o contexto cultural (MEYER, 2008).

O conceito de gênero, por sua vez, surgiu para se contrapor à ideia de uma essência (masculina ou feminina) natural, universal e imutável, enfatizando os processos de construção ou formação histórica, linguística e socialmente determinadas. A constituição de cada pessoa deve ser pensada como um processo que se desenvolve ao longo de toda a vida em diferentes espaços e tempos (FELIPE; GUIZZO, 2003, p. 120).

O processo de construção de marcadores de gênero não se limita à educação dada pela escola ou pelos pais, mas também inclui as mídias na formação cultural dos papéis de homens e de mulheres (MEYER, 2008). Por isso, o YouTube também tem participação nas construções sobre gênero. Os vídeos eram representações dos comportamentos masculinos e femininos. Esse aspecto condiz com a proposição de Swann (1992) de que os componentes verbais e visuais dos produtos midiáticos fazem parte dos referenciais de gênero para as crianças, criando assim "expectativas sociais" (SOUZA, 2006, p. 172). Além disso, para Butler (2002, p. 29), no âmbito dos estudos de gênero, em relação à construção, esta "não é apenas feita no tempo, mas é em si um processo temporário que ela opera através da reiteração de normas". Entendemos assim que a construção de marcadores de gênero é feita em diversos momentos com o intuito de estabelecer as regras sociais de comportamentos. Por isso, acreditamos que durante a infância as crianças estão incorporando esses marcadores o tempo todo dentro do contexto social e com a presença dos produtos midiáticos.

Posso te mostrar um vídeo aqui? Vão me achar guriazinha, mas não é. Porque é vídeo de [...] Eu vou escrever porque não quero falar. (O menino pesquisa por fadas). Esse vídeo aqui não dá muito medo, mas olha. Um pote de bala em cima da cama é normal, é quarto de guria e olha só, tá parecendo tipo uma borboleta, vindo voando. A primeira vez que eu vi, eu fiquei com medo. Parece que é real mesmo porque é uma cama normal (o vídeo mistura imagem real com animação). Olha os pés. Escuta a música. Música de terror. Tem uns trens que eu olho também. Outra coisa que vai parecer que eu sou guriazinha, mas não é. É de Tritão, sereia, essas coisas (Entrevista com a criança Gabriel, 2018, p. 2104).

4 As entrevistas com as crianças apresentadas neste artigo foram realizadas para a pesquisa doutoral "Apropriação por crianças da publicidade em canais de YouTubers brasileiros: a promoção do consumo no YouTube através da Publicidade de Experiência". 
A CONSTRUÇÃO SOCIAL DE GÊNERO PARA CRIANÇAS ATRAVÉS DO YOUTUBE

Esta fala do menino Gabriel $^{5}$ de 11 anos aponta que existe uma diferenciação entre meninos e meninas no âmbito do consumo cultural e midiático, presente no YouTube. Porém, ele não foi o único. Todas as 15 crianças de duas escolas públicas e participantes da pesquisa assistiam ao YouTube, sendo que nove delas assistem aos vídeos todos os dias e seis veem mais nos finais de semana. Mesmo com a enorme quantidade de conteúdos disponíveis na plataforma, existe uma clara divisão temática. As meninas assistiam a vídeos de YouTubers do sexo feminino, enquanto os meninos viam o oposto delas. As temáticas que mais interessaram às meninas envolviam maquiagem, bonecas, culinária e dança. Já para os meninos, futebol ${ }^{6}$ e videogames violentos ${ }^{7}$ estavam entre seus principais interesses no YouTube. Portanto, com as 15 crianças entrevistadas, observamos a reprodução da diferenciação de gênero em masculino e feminino, reforçada pelo consumo cultural e midiático das produções dos YouTubers.

Pensando no aspecto social imbricado à imagem corporal, com os vídeos indicados pelas crianças, tem-se a erotização dos corpos adolescentes e adultos femininos como forma de promoção dos canais no YouTube consumidos por elas, principalmente, ao gênero musical funk (Cia. Daniel Saboya e Gêmeas.com). Para além de um discurso moralista, é preciso entender que as adolescentes e as mulheres presentes nos canais citados participam do processo de publicização de seus corpos no YouTube. É o investimento no corpo para o sucesso. "A produção e a veiculação dos corpos infantis, de intervenções estéticas, de cuidados com a aparência e com a imagem, têm propiciado sua erotização e seu consumo" (BECK, 2013, p.142).

As meninas assistiam a dois canais de dança, com milhões de inscritos, Cia. Daniel Saboya e Gêmeas.com, ambos voltados para coreografias de funk e de sertanejo. Uma das músicas presente nos dois canais é intitulada "Ta Tum Tum", cuja letra contém o seguinte trecho: "A gata é uma loucura. Fazendo a proibida e mantém postura. Depois da meia-noite é filme com censura. Sensualidade pura. Gosta de fazer o 'tá, 'tá, 'tá, 'tá tum tum. Quicando e mostrando o poder desse bumbum". A música ficou conhecida por MC Kevinho, Simone e Simaria. Importante ressaltar que o canal Gêmeas.com é feito por duas adolescentes, que aparecem em roupas curtas nos vídeos, assim como as mulheres dançarinas no canal Cia. Daniel Saboya.

Logo, as meninas estão se apropriando de características femininas baseadas nos vídeos do YouTube e elas compartilham os conteúdos entre seus pares. As noções de beleza e de dança estão atreladas ao conhecimento sobre o que significa ser mulher na sociedade. O corpo feminino se torna um produto midiático para angariar inscritos, anunciantes e retornos monetários para os canais. Ou seja, o corpo é ressignificado para ser filmado a fim de atender os propósitos comerciais (ROSÁRIO, 2008). Ademais, ele é um objeto comunicacional (ROSÁRIO; COCA, 2017) que desencadeia uma rede de significações em quem o consume pelas mídias.

5 Nome fictício. Todas as crianças da pesquisa escolheram seus próprios pseudônimos.

6 Com destaque para a figura do jogador Neymar Jr., os meninos queriam jogar futebol como ele e pediam camisas de times e chuteiras.

70 mais citado foi o Grand Theft Auto (GTA), indicado para maiores de 18 anos. 
As crianças podem acreditar que essa erotização faz parte do "comportamento feminino" que é reforçado pelos inúmeros vídeos nos canais. Temos, ainda, a diferença de gênero, neste momento, de corpos expostos para monetização de vídeo no YouTube, pois são meninas e mulheres que usam roupas curtas e justas para dançar músicas com conotação sexual. "A menina vai perdendo as características infantis - leia-se, a inocência -, dando lugar ou incorporando outros jeitos de ser mulher" (FELIPE; GUIZZO, 2003, p. 126). Logo, a erotização dos corpos femininos se caracteriza como um reforço da cultura midiática que utiliza o corpo como forma de promoção de conteúdo no YouTube e de monetização, servindo a propósitos comerciais (ROSÁRIO, 2008). É aprendido assim que o corpo é um produto midiático e que a imitação dessas danças sensuais faz parte do imaginário feminino no Brasil, característica reforçada desde os anos 1980 e 1990 com apresentadoras em roupas curtas nos programas televisivos infantis e dançarinas de bandas como "É o tchan".

De acordo com Felipe (2008), desde a mídia impressa e a televisão, os corpos são inseridos como erotizados, principalmente o feminino, é um dos fatores que leva à construção de marcadores de gênero nas meninas. O YouTube é mais uma mídia que reforça isso. Por isso, é fundamental desconstruir com as crianças essas representações do corpo em troca de curtidas, comentários e visualizações, problematizando essas motivações.

Sabe uma coisa que eu aprendi? A minha mãe me disse, mas depois eu pesquisei no YouTube de novo. Sabe o que tu faz para não borrar? Tu pega o batom mesmo e vai fazendo a marquinha da boca. E depois tu passa o batom e não borra. Eu tô sempre fazendo isso e nunca borra. Tu pega a pontinha do batom [...] Sabe que o batom é meio torto né? Pega a ponta do batom e vai passando e depois tu passa o batom que não borra. (Entrevista com a criança Larissa, 2018, p. 210).

Outro aspecto do consumo midiático do YouTube relacionado com a imagem corporal envolve os vídeos de maquiagem vistos pelas meninas. Uma das crianças, Larissa, afirmou que aprendeu a passar batom nos lábios por causa de um vídeo no YouTube. Vemos então a inserção da maquiagem no cotidiano das crianças seja pelo vídeo ou pelo uso dos produtos, com as YouTubers adultas servindo de "inspiração" para as meninas.

Nesse sentido, temos a Natália, que ganhou diferentes produtos de maquiagem. Ao ver o vídeo da YouTuber/maquiadora Mari Maria, 27 anos, da qual é fã, fez a seguinte afirmação: "Ela tenta reproduzir maquiagem sem espelho. Olha como é a cara dela normal e olha como fica a maquiagem dela" (Entrevista com a criança Natália, 2018 p. 199). Assim, para a menina, a YouTuber só seria bonita com maquiagem que esconda suas sardas, consideradas como imperfeições.

Esses tipos de vídeos estão contribuindo para a adultização das meninas. Este conceito, defendido por Postman (1999) em relação à televisão, se aplica também ao YouTube, pois a adultização seria uma das consequências do acesso 
A CONSTRUÇÃO SOCIAL DE GÊNERO PARA CRIANÇAS ATRAVÉS DO YOUTUBE

das crianças a conteúdos midiáticos, ou seja, elas estariam vendo com as mídias assuntos voltados para o público adulto. Portanto, vemos a repetição da lógica televisiva de colocar o corpo feminino erotizado, tanto adulto quanto juvenil, para promover produtos midiáticos, conseguir mais likes e relevância dentro do YouTube ao mesmo tempo que contribui para o processo de adultização da infância.

Conforme propõe Felipe (2008), as meninas se preocupam mais com a aparência. Elas aprendem desde muito novas que a maquiagem é uma aliada para esconder seus defeitos e inseri-las no padrão de beleza vendido pelas imagens das YouTubers, que também representam o que é ser feminina socialmente. Essa questão é enquadrada na crítica ao "mito da beleza" de Wolf, pois

\begin{abstract}
As qualidades que um determinado período considera belas nas mulheres são apenas símbolos do comportamento feminino que aquele período julga ser desejável. O mito da beleza na realidade sempre determina o comportamento, não a aparência. A juventude e (até recentemente) a virgindade foram "bonitas" nas mulheres por representarem a ignorância sexual e a falta de experiência. O envelhecimento na mulher é "feio" porque as mulheres adquirem poder com o passar do tempo e porque os elos entre as gerações de mulheres devem sempre ser rompidos. [...] a nossa identidade deve ter como base a nossa "beleza", de tal forma que permaneçamos vulneráveis à aprovação externa, trazendo nosso amor-próprio, esse órgão sensível e vital, exposto a todos (WOLF, 1992, p. 17).
\end{abstract}

Por isto, quando as meninas nas escolas procuravam vídeos de maquiagem, elas estavam repetindo a lógica desse mito, em busca de aprovação, de serem consideradas belas. Elas acreditavam fazer parte do papel social feminino saber se maquiar, esconder "imperfeições" e desejarem ter os corpos das YouTubers para usarem as determinadas roupas que observavam nos vídeos. Logo, a questão corporal inclui normas reguladoras sobre gênero (BUTLER, 2002).

Importante ressaltar que, ao mesmo tempo que as meninas procuravam esses tipos de vídeos acima, elas também viam e desejavam ter bonecas como Baby Alive ${ }^{8}$ e Bebê Reborn ${ }^{9}$. Ambas se caracterizam por se aproximarem da aparência a um bebê de verdade, reforçando os papéis maternais, de cuidado com a família e funções reprodutoras que supostamente são responsabilidade única das mulheres (SCOTT, 1995).

Enquanto as meninas estavam envolvidas nas questões corporais, quase todos os meninos (seis) focavam em vídeos sobre futebol. Eles ansiavam pelo momento do intervalo para irem jogar e a aula favorita era a Educação Física, em que podiam praticar lances que assistiam nos vídeos dos craques desse esporte ou até mesmo em canais de outros meninos falando sobre o futebol.

Para Neymar, ver vídeos do seu jogador favorito é a principal razão de acesso ao YouTube: "Quando eu fui saber que tinha YouTube, bá. Eu pensei:

8 Boneca da marca Hasbro que imita ações de bebês como comer e beber.

9 Sua fabricação é manual e existem cursos que ensinam a fazer a boneca artesanalmente. Por isso, seu preço é elevado, entre $R \$ 200$ a mais de $R \$ 3.000$. 
"vou ver vídeo, vou ver o Neymar, vou ver qualquer coisa". Eu amo ver jogador de futebol. Eu gosto de jogar futebol. Eu amo, é a única coisa que eu amo". Para o menino, o YouTube o aproxima de seu sonho de ser jogador de futebol e dos seus ídolos, os jogadores Neymar, Messi e Cristiano Ronaldo, através dos vídeos.

Além desse esporte, todos os meninos tinham interesse em videogames, principalmente no GTA, sendo capazes de verem vídeos de gameplay por horas. Segundo o Mateus (Entrevista com a criança MATEUS, 2018, p. 207), "GTA é um joguinho que nós explode ${ }^{10}$ muito as pessoas, nós somos livres no mundo, só que é bem legal o jogo. Tem como matar a polícia, a polícia vai atrás de ti". É importante salientar que este jogo é para maiores de 18 anos pelas cenas de violência e nele predominam as figuras masculinas como principais autores das ações dentro da narrativa. A fala de Mateus, 10 anos, é um exemplo de como o acesso a esse tipo de jogo reforça o papel masculino de dominação, simulando uma realidade que o homem pode fazer qualquer coisa, dentro dos privilégios da "masculinidade patriarcal" (HOOKS, 2018, p. 107). Essa noção de dominação masculina vai contra a necessidade humana de expor sentimentos e o estímulo à autoestima, podendo causar frustrações e angústias nos meninos e nos homens (HOOKS, 2018).

As relações de gênero representadas pela mídia são campos de constituição de identidades, de produção e reprodução de representações e, portanto, espaço educativo onde imagens de crianças, adolescentes, mulheres e homens podem ser consumidas tendo como referencial modelos social, econômico e cultural hegemônicos (SABAT, 2008, p. 153).

Desse modo, as crianças, ao verem os vídeos no YouTube, estão estabelecendo características para seus próprios marcadores de gênero. Quando Santi (2011, p. 111) afirma que "o que é aprendido é assistir" em relação ao consumo de televisão, podemos estender essa noção para o YouTube. $O$ consumo midiático (TOALDO; JACKS, 2013), aquele é ofertado pelas mídias, está presente no cotidiano das crianças através do YouTube e de seus diferentes tipos de conteúdo. Elas estão se apropriando de diferentes formas de papéis sociais como meninos e meninas. Daí a relevância de problematizar a questão de gênero como forma de "compreender as complexas conexões entre várias formas de interação humana" (SCOTT, 1995, p. 89). O YouTube, por mais que ofereça diferentes conteúdos, vai ter seu consumo midiático apresentado de acordo com os interesses dos sujeitos. Logo, quando as crianças separam suas escolhas por vídeos de futebol, GTA (meninos) e maquiagem, bonecas e tarefas domésticas (meninas), elas estão representando as diferenciações de gênero que são construídas socialmente.

\section{Considerações finais}

Foi possível perceber que as crianças estão aprendendo a elaborar suas

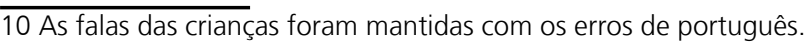


A CONSTRUÇÃO SOCIAL DE GÊNERO PARA CRIANÇAS ATRAVÉS DO YOUTUBE

noções de gênero e os YouTubers corroboram esse processo. Logo, por mais que as crianças tivessem curiosidade por diferentes temas, chamou a atenção o fato de ainda existir uma divisão de gênero, "coisas que meninas gostam" - bonecas, maquiagem, cozinhar; e "coisas que meninos gostam" - futebol e videogames.

Dessa maneira, o YouTube está na esfera do consumo cultural e midiático que oferece aos sujeitos representações sobre o mundo através dos vídeos. As crianças participam ativamente desse processo, assistindo e compartilhando entre os pares o que aprendem com os vídeos. Por isso, a plataforma pode ser um espaço de construção de marcadores de gênero para as crianças, já que os YouTubers fazem parte da sociedade brasileira e apresentam suas características culturais através dos vídeos.

A linguagem, as imagens, os corpos dos YouTubers expressam comportamentos sociais vistos na sociedade e os instituem para quem assiste aos conteúdos, ou seja, essas práticas são demonstradas e reforçadas pelos vídeos como padrões sociais, o que influencia no processo de delimitação de diferenças e aproximações entre meninos e meninas.

É fundamental salientar que entendemos o conceito de gênero como plural para além da dualidade feminino/masculino (MEYER, 2008). Acreditamos também na proposição de Scott (1995), que afirma que papéis masculinos e femininos são inconstantes e variam de acordo com o contexto social. Porém, tomamos essa dicotomia como discussão inicial para incentivar as crianças a refletirem sobre o que lhes é apresentado baseado nesta divisão de gênero.

Neste amplo campo de discussão sobre gênero e infância, o mais importante é ouvir as crianças para incentivá-las à desconstrução de limites denominados "coisas de menino e de menina". Logo, para termos uma sociedade mais igualitária é necessário trabalharmos com as crianças o entendimento sobre a complexidade e a diversidade do ser humano, de forma a respeitar todas as pessoas, independentemente da sua identidade de gênero.

\section{Referências}

ALCÂNTARA, Alessandra. O brincar em ambiente virtual: jogar, postar, conversar. In: ALCÂNTARA, Alessandra; GUEDES, Brenda (Org.). Comunicação e infância: processos em perspectiva. São Paulo: Pimenta Cultural, 2017.

BECK, Dinah. Com que roupa eu vou? Consumo e erotização nos uniformes escolares infantis. In: FELIPE, Jane; GUIZZO, Bianca; BECK, Dinah (Orgs.). Infância, gênero e sexualidade nas tramas da cultura e da educação. Canoas: Editora ULBRA, 2013.

BOYD, Danah; ELLISON, Nicole. Social network sites: definition, history, and scholarship. Journal of ComputerMediated Communication, v. 13, n. 1, p. 210-230, 2007.

BURGESS, Jean; GREEN, Joshua. YouTube e a revolução digital: como o maior fenômeno da cultura participativa está transformando a mídia e a sociedade. São Paulo: Aleph, 2009.

BUTLER, Judith. Cuerpos que importan: sobre los límites materiales y discursivos del "sexo". Buenos Aires: Paidós, 2002. 
CANCLINI, Nestor. Consumidores e cidadãos: conflitos multiculturais da globalização. 4. ed. Rio de Janeiro: Editora UFRJ, 1999a.

CANCLINI, Nestor. El consumo cultural: una propuesta teórica. In: SUNKEL, Guillermo (Org.). Consumo cultural en América Latina. Santafé de Bogotá: Convenio Andrés Bello, 1999b.

CORSARO, William. Sociologia da infância. Porto Alegre: Artmed, 2011.

DIJCK, José Van. The culture of connectivity: a critical history of social media. 2 ed. Nova lorque: Oxford, 2013.

FANTIN, Monica. "Nativos e imigrantes digitais" em questão: crianças e competências midiáticas na escola". Passagens, v. 7, n. 1, 2016, p. 5-26.

FANTIN, Monica. "Crianças, dispositivos móveis e aprendizagens formais e informais". Educação temática digital, v. 20, n. 1, 2018, p. 66-80.

FELIPE, Jane; GUIZZO, Bianca. Erotização dos corpos infantis na sociedade do consumo. Pro-posiç̧̃es, v. 14, n. 3, set./dez. 2003.

FELIPE, Jane. Erotização dos corpos infantis. In: LOURO, Guacira; FELIPE, Jane; GOELLNER, Silvana (Orgs.). Corpo, gênero e sexualidade: um debate contemporâneo na educação. Petrópolis: Vozes, 2008.

FELIPE, Jane; GUIZZO, Bianca; BECK, Dinah (Orgs.). Infância, gênero e sexualidade nas tramas da cultura e da educação. Canoas: Editora ULBRA, 2013.

FLICK, Uwe. Introdução à pesquisa qualitativa. Porto Alegre: Artmed, 2009.

FRANÇA, Vera. O acontecimento e a mídia. Galáxia, São Paulo, v. 12, n. 24, p. 10-21, dez. 2012.

HOOKS, Bell. O feminismo é para todo mundo: políticas arrebatadoras. Rio de Janeiro: Rosa dos Tempos, 2018.

JENKINS, Henry. Cultura da convergência. 2 ed. São Paulo: Aleph, 2009.

JENKINS, Henry; ITO, Mizuko, BOYD, Danah. Participatory culture in a networked era: a conversation on youth, learning, commerce, and politics. Cambridge, UK: Polity Press, 2016. Documento disponível para Kindle.

KYNCL, Robert; PEYVAN, Maany. Streampunks: how YouTube and the new creators are transforming our lives. Londres: Penguim Random House, 2017. Documento disponível para Kindle.

LANGE, Patricia. Videos of affinity on YouTube. In: SNICKARS, Pelle; VONDERAU, Patrick (Org.). The YouTube Reader. Stockholm: Mediehistoriskt, 2009.

MARINHO, Maria Helena. Pesquisa Video Viewers: como os brasileiros estão consumindo vídeos em 2018". Think with Google, 2018. Available on: <https://goo.gl/oBzbKp>. Acess date: October, 14th. 2018.

MEYER, Dagmar. Gênero e educação: teoria e política. In: LOURO, Guacira; FELIPE, Jane; GOELLNER, Silvana (Orgs.). Corpo, gênero e sexualidade: um debate contemporâneo na educação. Petrópolis: Vozes, 2008.

MIGLIORA, R.; FISCHBERG, J. O vício de ver tevê. In: DUARTE, R. (Org.). A televisão pelo olhar das crianças. São Paulo: CORTEZ, 2008.

MONTIGNEAUX, Nicolas. Público-alvo: crianças - a força dos personagens e do marketing para falar com o consumidor infantil. Rio de Janeiro: Campus, 2003.

NÚCLEO DE INFORMAÇÃO E COORDENAÇÃO DO PONTO BR (NIC.br) (Org.). Pesquisa sobre o uso da internet por crianças e adolescentes no Brasil: TIC Kids On-line Brasil 2016. São Paulo: Comitê Gestor da Internet no Brasil, 2017. Available on: < http://cetic.br/publicacao/pesquisa-sobre-o-uso-da-internet-por-criancas-eadolescentes-no-brasil-tic-kids-online-brasil-2016/>. Acess date: December, 23th. 2017.

NÚCLEO DE INFORMAÇÃO E COORDENAÇÃO DO PONTO BR (NIC.br) (Org.). Pesquisa sobre o uso da internet por crianças e adolescentes no Brasil: TIC Kids On-line Brasil 2018. São Paulo: Comitê Gestor da Internet no Brasil, 2019. Available on: < https://cetic.br/publicacao/pesquisa-sobre-o-uso-da-internet-por-criancas-eadolescentes-no-brasil-tic-kids-online-brasil-2018/>. Acess date: December, 20th. 2019.

OROZCO GOMEZ, Guillermo. Entre telas: novos papéis comunicativos e educativos dos cidadãos. In: APARICl, Roberto (Org.). Educomunicação: para além do 2.0. São Paulo: Paulinas, 2014.

OROZCO GOMEZ, Guillermo. Mediaciones familiares y escolares em la recepción televisiva de los niños. (Algunos hallazgos recientes). Comunicación y sociedad, n. 13, set-dec. 1991, p.113-129. 
A CONSTRUÇÃO SOCIAL DE GÊNERO PARA CRIANÇAS ATRAVÉS DO YOUTUBE

PALFREY, John; GASSER, Urs. Born digital. New York: Basic Books, 2008.

POMPEU, Bruno. "Os significados do consumir em tempos de redes sociais: comprar, vincular, curtir?" In: ATEM, Guilherme; OLIVEIRA, Thaiane; AZEVEDO, Sandro (Orgs.). Ciberpublicidade: discurso, experiência e consumo na cultura transmidiática. Rio de Janeiro: E-papers, 2014.

POSTMAN, Neil. O desaparecimento da infância. Rio de Janeiro: Graphia, 1999.

PRENSKY, Marc. Digital natives, digital immigrants. On the horizon, MCB University Press, v. 9, n. 5, p. 1-6, out. 2001.

QVORTRUP, Jens. A infância enquanto categoria estrutural. Educação e pesquisa, São Paulo, v. 36, n. 2, p. 631643, 2010.

ROSA, Maria Virginia; ARNOLDI, Maria Aparecida. A entrevista na pesquisa qualitativa: mecanismos de avaliação de resultados. Belo Horizonte: Autêntica, 2008.

ROSÁRIO, Nísia Martins do. A cartografa como um mapa movente para a pesquisa em comunicação. Comunicação e inovação, v. 19, n. 41, p. 34-48, set-dez. 2018.

ROSÁRIO, Nísia Martins do. Imagens midiáticas em corpos eletrônicos. Intexto, v. 1, n. 18, p. 1-13, jan-mai. 2008.

ROSÁRIO, Nísia Martins do; COCA, Adriana. O paradoxo publicitário na televisão brasileira: atualizando dissidência de gênero num mundo uniforme. Journal on Semiotics and Culture, n. 3, p. 7-19, 2017.

ROSÁRIO, Nísia Martins do; AGUIAR, Lisiane. Implosão midiática: corporalidades nas configurações de sentidos da linguagem. Significação, v. 41, n. 42, p. 166-185, 2014.

SABAT, Ruth. Gênero e sexualidade para consumo. In: LOURO, Guacira; FELIPE, Jane; GOELLNER, Silvana (Orgs.). Corpo, gênero e sexualidade: um debate contemporâneo na educação. Petrópolis: Vozes, 2008.

SANTI, Pedro Luiz. Desejo e adição nas relações de consumo. São Paulo: Zagodoni, 2011.

SAYÃO, Deborah. Pequenos homens, pequenas mulheres? Meninos, meninas? Algumas questões para pensar as relações entre gênero e infância. Pro-posições, v. 14, n. 3, p. 67-87, set-dez. 2003.

SCOTT, Joan. Gênero: uma categoria útil de análise histórica. Educação e realidade, v. 20, n. 2, p. 71-99, 1995.

SNICKARS, Pelle; VONDERAU, Patrick (Org.). The YouTube Reader. Stockholm: Mediehistoriskt, 2009.

SOUZA, Érica. Marcadores sociais da diferença e infância: relações de poder no contexto escolar. Cadernos Pagu, $\mathrm{n}$. 26, p. 169-199, jan-jun. 2006.

SOUZA, Marco Antonio. A infância na mídia: desvendando essa história. In: SOUTO, Kely; SOUZA, Marco Antonio; TOSTA, Sandra; VIANNA, Graziela; RIBEIRO, Ruth (Orgs.). Infância na mídia. Belo Horizonte: Autêntica, 2009.

SWANN, Joan. Girls, boys and language. Oxford: Backwell, 1992.

TOALDO, Mariangela. JACKS, Nilda. Consumo midiático: uma especificidade do consumo cultural, uma antessala para os estudos de recepção. In: ENCONTRO ANUAL DA COMPÓS, 22, 2013, Salvador, Associação Nacional dos Programas de Pós-Graduação em Comunicação. Anais... Salvador: Associação Nacional dos Programas de Pós-Graduação em Comunicação, 2013.

TOFFLER, Alvin. The third wave. Nova York: Bantam Books, 1980.

WOLF, Naomi. O mito da beleza: como as imagens de beleza são usadas contra as mulheres. Rio de Janeiro: Rocco, 1992. 